\section{Gategory}

Synthesis of Materials and Unnatural Products

\section{Key words}

photomodulation

magnetic bistability

porphyrins

SYNFACTMthe

S. VENKATARAMANI, U. JANA, M. DOMMASCHK, F. D. SÖNNICHSEN, F. TUCZEK, R. HERGES* (UNIVERSITY OF KIEL, GERMANY)

Magnetic Bistability of Molecules in Homogeneous Solution at Room Temperature

Science 2011, 331, 445-448.

\title{
Lights, Magnets, Action!
}

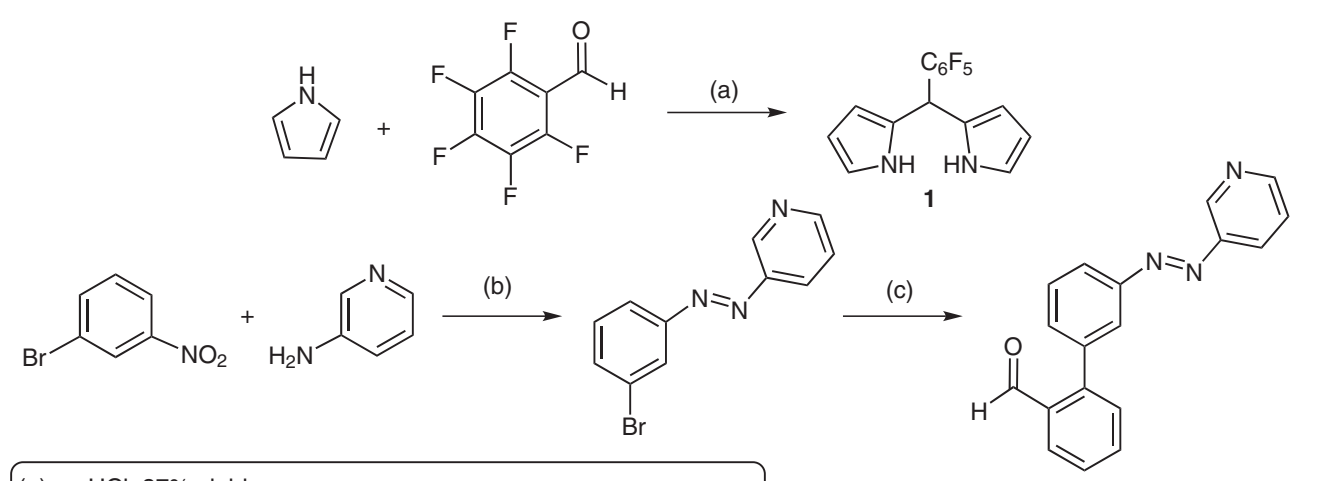

(a) aq $\mathrm{HCl}, 37 \%$ yield

(b) $40 \% \mathrm{NaOH}, \mathrm{PhMe}, 35 \%$ yield

(c) 2-formylphenyl boronic acid, EtOH, $\mathrm{K}_{2} \mathrm{CO}_{3}, \mathrm{Pd}\left(\mathrm{PPh}_{3}\right)_{4}, 95 \%$ yield

(d) $1, \mathrm{BF}_{3} \cdot \mathrm{OEt}_{2}, p$-chloranil, TEA, $\mathrm{CHCl}_{3}, 7 \%$ yield

(e) Ni(acac) $)_{2}, \mathrm{PhMe}, 73 \%$ yield

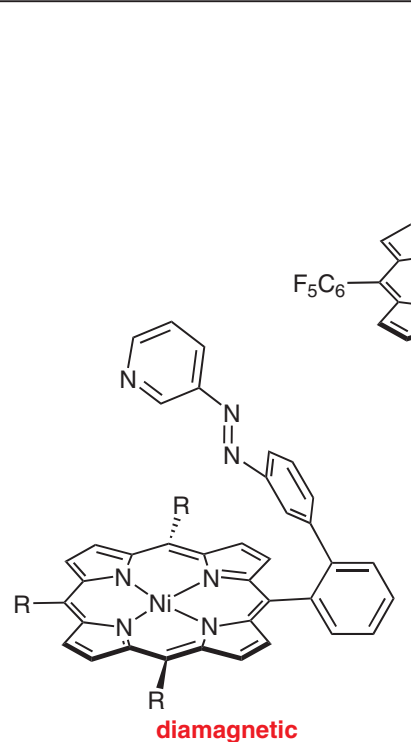

$\underset{h v(435 \mathrm{~nm})}{\stackrel{h v(500 \mathrm{~nm})}{\stackrel{(}{\rightleftarrows}}}$

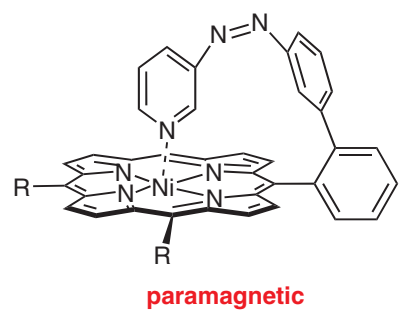

Significance: This work describes the synthesis of a phenylazopyridine (PAP) decorated porphyrin system. The resulting pophyrin derivative is diamagnetic when the PAP arm is in the trans geometry. Upon irradiation, the PAP isomerizes to the cis form yielding a paramagnetic complex.
Comment: The authors have created a simple but elegant system with controllable magnetic properties. The porphyrin is capable of cycling between the two states over 10,000 cycles with no observed degradation. Preliminary results suggest this complex may be promising as an MRI contrast agent. 